\title{
Application of Fuzzy Logic in Multi-Mode Driving for a Battery Electric Vehicle Energy Management
}

\author{
T.A.T. Mohd ${ }^{1,4}$, M.K. Hassan ${ }^{1,2}$, Ishak Aris ${ }^{1}$, Azura C.S. ${ }^{1}$ and B.S.K.K Ibrahim ${ }^{3}$ \\ ${ }^{I}$ Department of Electrical and Electronic Engineering, Faculty of Engineering, Universiti Putra Malaysia, 43400 Serdang, Selangor, \\ Malaysia \\ ${ }^{2}$ Institut Teknologi Maju, Universiti Putra Malaysia, Malaysia \\ ${ }^{3}$ Department of Mechatronic Engineering and Robotics, Faculty of Electrical and Electronics Engineering, Universiti Tun Hussein Onn \\ Malaysia, Malaysia \\ ${ }^{4}$ Politeknik Kuala Terengganu, Malaysia \\ E-mail: tengkuazman78@gmail.com,khair@upm.edu.my
}

\begin{abstract}
Energy management system is an area of emerging interest in a full electric vehicle research. With the increasing moves to a more sustainable vehicle, there is a need to extend the battery range that simultaneously satisfying the conflicting demand between battery capacity and vehicle weight or volume. This paper presents a research conducted in the Universiti Putra Malaysia, focusing on the energy management strategy of a battery-powered electric vehicle. Three vehicle driving modes; sport, comfort, and eco have been individually modelled. Each mode is capable to dominate different driving environments; highway, suburban, and urban. In European driving cycle simulation test, comfort and eco modes have shown large extension in driving range with the maximum of $7.33 \%$ and $19.70 \%$ respectively. However the speeds have been confined by certain specific limits. The proposed of integrated multimode driving using fuzzy logic has enabled an adaptive driving by automatically select the driving parameters based on the speed conditions. The results have proven its ability in reducing the energy consumption as much as $32.25 \%$, and increasing the driving range of $4.21 \%$ without downgrading the speed performance.
\end{abstract}

Keywords - battery electric vehicle; energy management; fuzzy logic controller; multi-mode driving.

\section{INTRODUCTION}

Massive production of conventional internal combustion vehicles (ICEV) in vehicle population has increased worldwide concerns on energy conservation and environment protection. In search for sustainable transportation, battery electric vehicle (BEV) has been identified as one of the potential candidate. BEV does not only offer appropriate solution to emission problems in relation to transportation and energy crisis, but it also offers many advantages in term of performance, energy efficiency, noiseless, less maintenance and can be regulated by power grid operator [1-4]. However, the key challenge in BEV is the limitation in driving range since BEV relies on battery as its sole energy source. The battery therefore, must contain sufficient energy to drive certain range and supply all loads; propulsion and auxiliary loads. By simply increase the size of battery in order to enhance the energy capacity will only imply a penalty to the vehicle weight and volume. A promising way to increase the range is by implementing energy management system (EMS) to manage the energy by controlling and coordinating the power generation, energy storage and power flow within components to achieve maximum system efficiency [4]. Vehicle driving mode designs are basically based on the driver's driving styles, appropriate driving environments, vehicle types and its EMS strategy. Hybrid EV (HEV) such as BMW i8 [5] and Toyota Prius [6] benefit a wide option in modes as they possess a secondary propulsion power source which is not available in BEV, such as Mitsubishi i-MiEV [7] or Nissan Leaf [8]. Available modes in HEV vary from high performance mode (i.e. sport mode) to high efficiency mode (i.e. eco mode). However in BEV, the mode priority is given to sustain the energy for a better range; varies from standard driving mode to aggressively energy regenerating in braking mode. Examples of driving modes available in the commercial electric vehicle are presented in Table 1. Eco-driving is a driving strategy that maximizes energy efficiency in order to extend the vehicle's range [9]. At this very moment, many researches have put their focus on improving eco-driving mode [9-11]. For instance, Frank, R., G. Castignani, R. Schmitz and T. Engel [9] proposed an eco-driving mode 
application for EV using android devices. Kim, Y., I. Lee and S. Kang [10] proposed an eco-assist techniques through real-time monitoring of BEV energy usage efficiency. Later, Vatanparvar, K. and M.A.A. Faruque [11] have proposed an eco-friendly automotive climate control and navigation system to extend battery lifetime and driving range of EV. The deployment of eco-driving in EV has successfully extended the vehicle's range up to approximately $20 \%$; subject to constraints of maximum speed, comfort level, as well as regenerative braking energy.

UPM-EV research team has conducted a research in Universiti Putra Malaysia (UPM), focusing on multi-mode driving of a BEV based on EMS. Unlike other previous works, this research intends to integrate the available driving modes into a multi-mode driving that is automatically triggered by the driving speed limits. It is expected that, the vehicle can benefits the diverse advantages in each mode without downgrading its speed performance. The vehicle, BEV-001 is specifically designed with adaptation to Malaysia local environment and social requirements. The technical specifications of the BEV-001 are as shown in Table II. In this research, the vehicle simulation model was the improved model adopted from our previous research in BEV [2-3]. Four driving modes have been designed and integrated into the vehicle based on the energy management strategy; sport mode, comfort mode, eco mode, and artificial intelligent (AI) mode. Fuzzy logic has been employed in the AI mode to implement a multi-mode driving due to its advantages of having simple structure and small computation time [12]. The significance of each mode towards the extension in range is then tested and compared in simulation test using new European driving cycle (NEDC) [13].

TABLE I

DRIVING MODES OF COMMERCIAL ELECTRIC VEHICLE

\begin{tabular}{|l|l|}
\hline Manufacturer /Model & Driving modes \\
\hline BMW i8 (HEV) & (3): Sport, comfort, eco pro \\
\hline Toyota Prius Gen 3 (HEV) & (4): Power, normal, eco, EV \\
\hline BMW i3 (BEV) & (3): Comfort, eco pro, eco pro+ \\
\hline Mitsubishi i-MiEV (BEV) & (3): Drive, eco, B \\
\hline Nissan Leaf (BEV) & (4): Drive, drive +eco, B-mode, B-mode +eco \\
\hline BMW i8 (HEV) & (3): Sport, comfort, eco pro \\
\hline
\end{tabular}

TABLE II

BEV-001 TECHNICAL SPECIFICATIONS

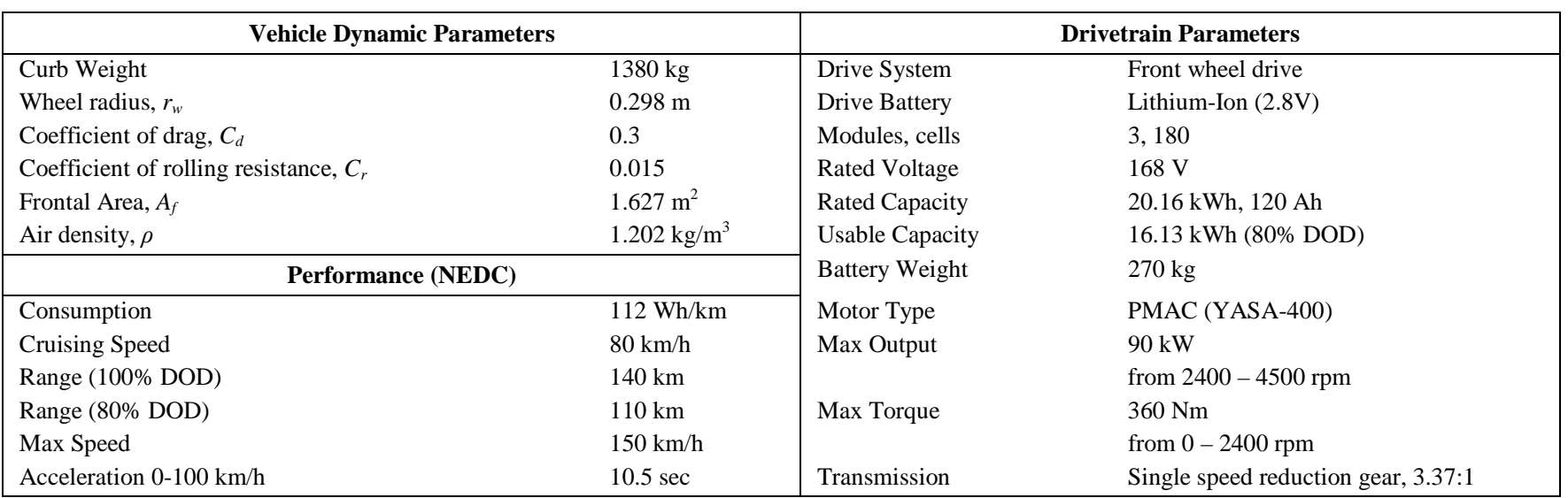

\section{MATERIALS AND METHODS}

\section{A. Simulink modelling of BEV-001}

The modelling of BEV-001 has been performed in the Matlab-Simulink environment. The vehicle is configured according to Fig. 1 and consists of; high voltage (HV) battery pack, low voltage (LV) battery, power electronic converter and inverter, onboard charger, propulsion load (electric motor), mechanical transmission, HV auxiliary load and LV auxiliary load. The mathematical equations for HV battery state of charge (SOC) and permanent magnet AC motor (PMAC) are given as follows;

SOC for HV battery cell,

$$
\text { SOC }=\frac{E_{\max }[j]-E_{\text {emmomadi }}[j]}{\left.E_{\max }[]\right]} \times 100 \%
$$

where; $E_{\max }[\mathcal{l}]=$ maximum energy capacity in Joule, and $\boldsymbol{E}_{\text {usd }}[\boldsymbol{\eta}]=$ consumed energy in Joule.

PMAC electromagnetic torque,

$$
T_{e m}=k_{\varepsilon}\left[f\left(\theta_{c}\right) i_{a}+f\left(\theta_{e}-\frac{2 \pi}{3}\right) i_{b}+f\left(\theta_{e}-\frac{4 \pi}{3}\right) i_{c}\right]
$$

where; $k_{e}=$ motor torque constant, $\theta_{e}=$ rotor angle, and $i_{a}, i_{-}, i_{a}=$ phase currents from inverter.

PMAC takes 3-phase input current form inverter and rotor rotational speed from gearing in order to produce torque and power based on motor efficiency map, as shown in the 
following Fig. 2. The dynamic model for BEV-001 is based on $[3,14]$ as in the following equations;

$$
\begin{gathered}
M \frac{d V}{d t}=F_{t}-\left(F_{r r}+F_{a d}+F_{h}\right) \\
F_{r r}=M g C_{r} \cos \alpha \\
F_{a d}=\frac{1}{2} \rho A_{f} C_{d} V^{2} \\
F_{h c}=M g \sin \alpha
\end{gathered}
$$

where;

$M=$ vehicle curb weight,

$\frac{d v}{d t}=$ vehicle linear acceleration along longitudinal direction,

$F_{t}=$ traction force, $\mathbb{F}_{r y}=$ rolling resistance force,

$F_{a d}=$ aerodynamic drag force, $F_{h c}=$ hill climbing force,

$C_{r}=$ tire rolling resistance coefficient,

$\theta=$ gravitational acceleration, $\alpha=$ slope angle of the road,

$\rho=$ air density, $A_{f}=$ vehicle frontal area,

$C_{d}=$ aerodynamic drag coefficient, and $V=$ vehicle speed.

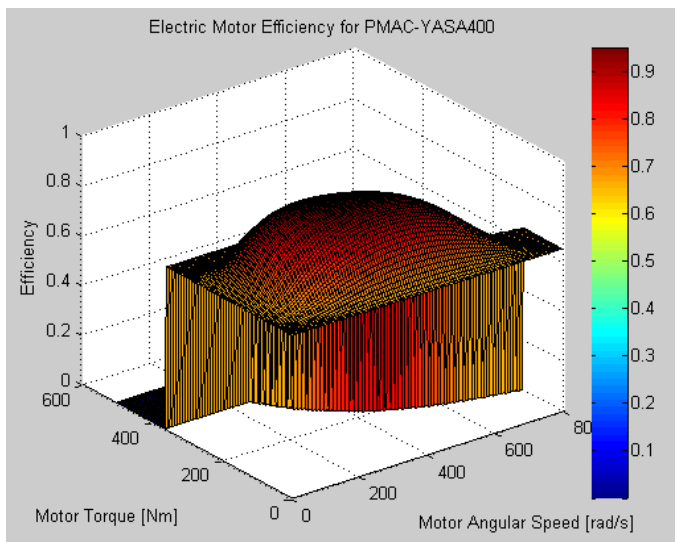

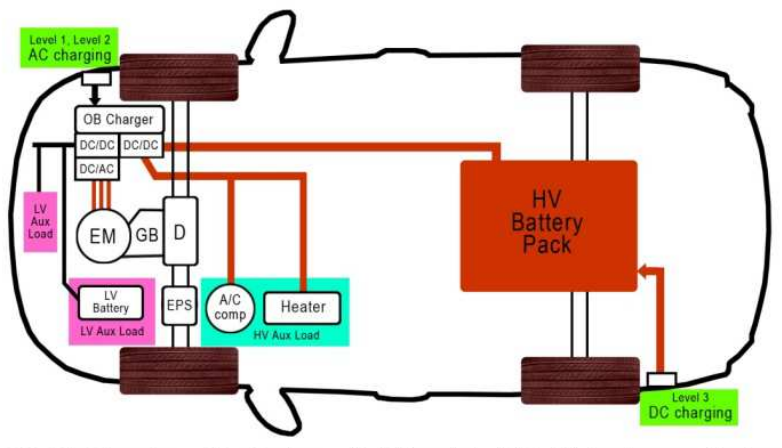

EM - Electric motor GB - Gearbox D - Differential EPS - Electronic power steering $\mathrm{OB}$ - Onboard

HV - High voltage LV - Low voltage Aux - Auxiliary

Fig. 1 Component configuration of BEV-001

The complete Simulink model of BEV-001 is presented in following Fig. 3. In order to validate the model performance with the actual commercialized vehicle, performance test has been employed to this model and the performance comparisons are presented in Table III.

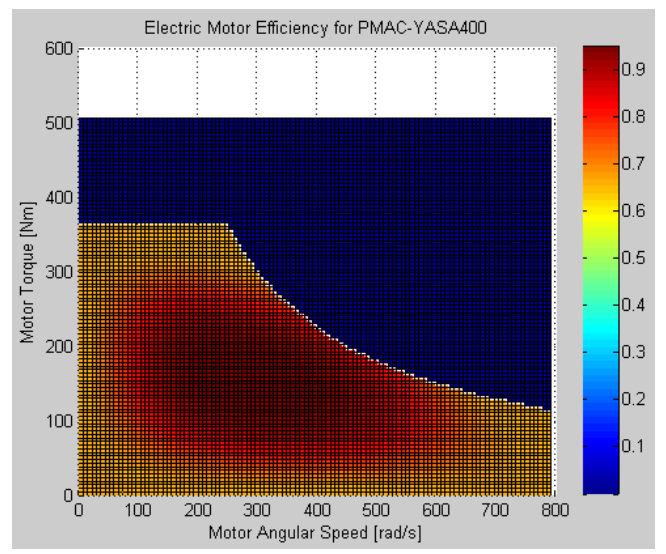

Fig. 2 Efficiency map for PMAC YASA-400 model in Matlab [16]

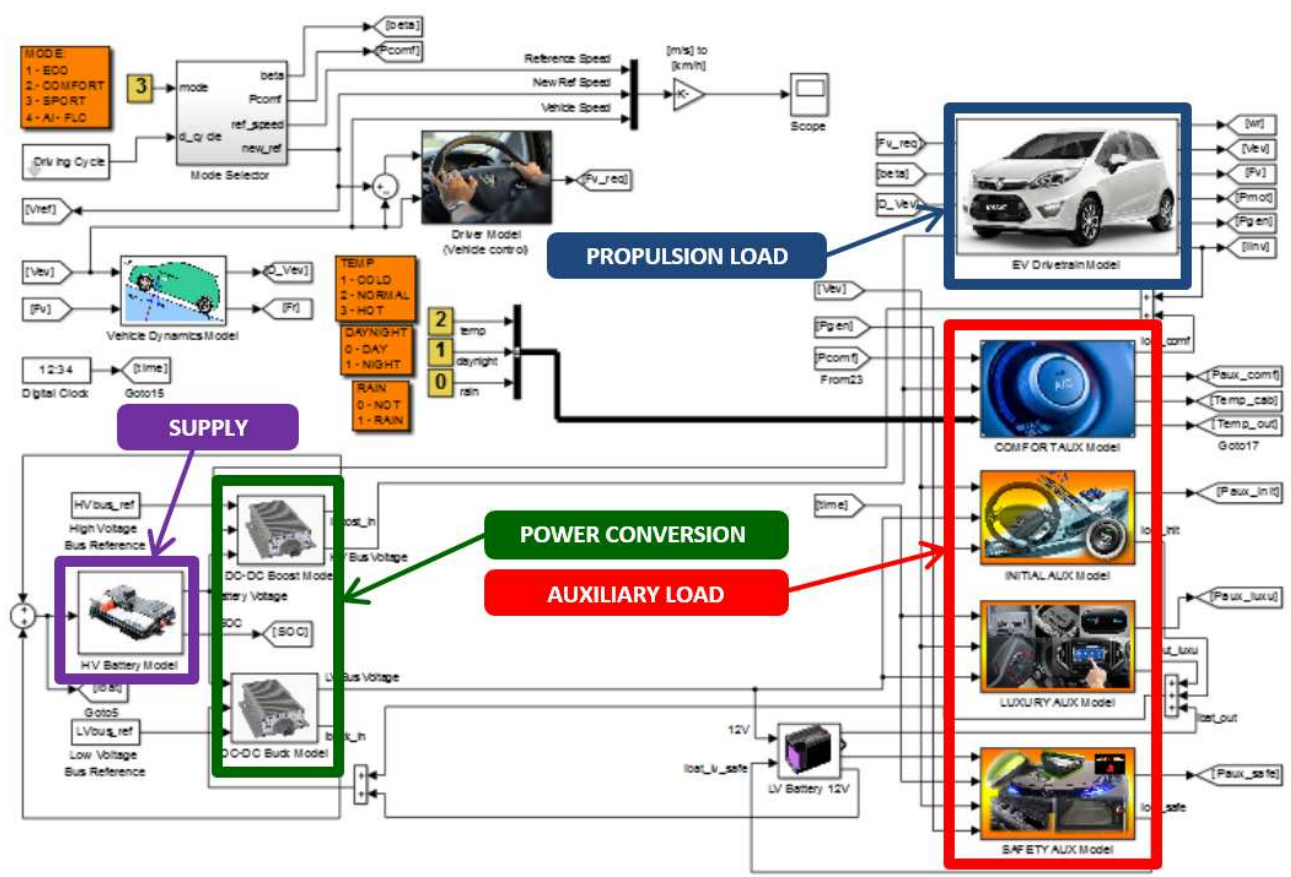

Fig. 3 Simulink model of BEV-001 
TABLE III

MODEL PERFORMANCE COMPARISON WITH LG-PROTON IRIZ BEV

\begin{tabular}{|lrr|}
\hline Performance Parameter & LG-Proton Iriz BEV & BEV-001 \\
\hline Li-Ion Capacity & $39.6 \mathrm{kWh}, 100 \mathrm{Ah}$ & $20.16 \mathrm{kWh}, 120 \mathrm{Ah}$ \\
Consumption (NEDC) & $132 \mathrm{Wh} / \mathrm{km}$ & $144 \mathrm{Wh} / \mathrm{km}$ \\
Range NEDC (100\% DOD) & $300 \mathrm{~km}$ & $140 \mathrm{~km}$ \\
Range NEDC (80\% DOD) & $240 \mathrm{~km}$ & $110 \mathrm{~km}$ \\
PMAC Pmax / Tmax & $116 \mathrm{~kW} / 360 \mathrm{Nm}$ & $90 \mathrm{~kW} / 360 \mathrm{Nm}$ \\
Maximum Speed & $150 \mathrm{~km} / \mathrm{h}$ & $150 \mathrm{~km} / \mathrm{h}$ \\
Acceleration 0-100 km/h & $9 \mathrm{sec}$ & $10.5 \mathrm{sec}$ \\
\hline
\end{tabular}

According to the above table, the performance of our simulation model is closely matched the actual LG-Proton Iriz BEV. Half capacity of Li-Ion batteries in BEV-001 is able to provide half driving range of actual BEV in NEDC. The maximum speed of the model perfectly matched the actual BEV, while the acceleration is slightly better in the actual BEV due to the better rating of maximum power in electrical motor (PMAC) model used. Based on the table, it can be assumed that the simulation model can be further applied for the implementation of energy management system strategy.

\section{B. Modelling of supply-load topology}

Regardless any drivetrain layouts, BEV basically consists of three major subsystems; energy source (supply), propulsion load, and auxiliary load [14]. The supply-load topology for our model is as presented in Fig. 4. The HV battery pack is a lithium-ion battery based on Winston Battery model WB-LYP40AHA [15]. The battery pack comprise of three modules, where a module consist of threeparallel and 20-serial $(3 \mathrm{P}, 20 \mathrm{~S})$ cells connections. These connections will increase the pack Ah capacity from $40 \mathrm{Ah}$ to $120 \mathrm{Ah}$ and nominal voltage from $56 \mathrm{~V}$ to $168 \mathrm{~V}$. The DC-DC converter is to increase or decrease the voltage from the HV traction battery to suit the voltage requirement of the loads. Two types of DC-DC converters are used; boost converter, and buck converter. Both are assumed operating in continuous mode.

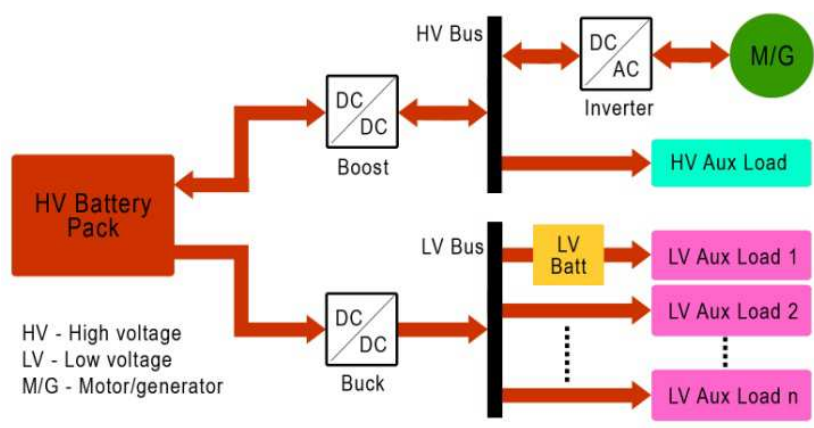

Fig. 4 Supply-load topology of Iriz BEV

The propulsion load is PMAC model YASA-400 from YASA Motors [16]. This motor possesses a high torque and power density capability that suitable for EV applications. This AC motor works together with an inverter, that controls the input and output parameters of the motor. The auxiliary loads are loads that accomplish either necessary or desired aspects of vehicle operation [14]. These loads are clustered into four groups; initial load, comfort load, safety load and luxury load, based on their performed functions as in Fig. 5 below. All auxiliary loads are supplied by the HV battery pack through power buses (HV and LV) except for the safety load, which is fed by the LV battery for safety purposes.

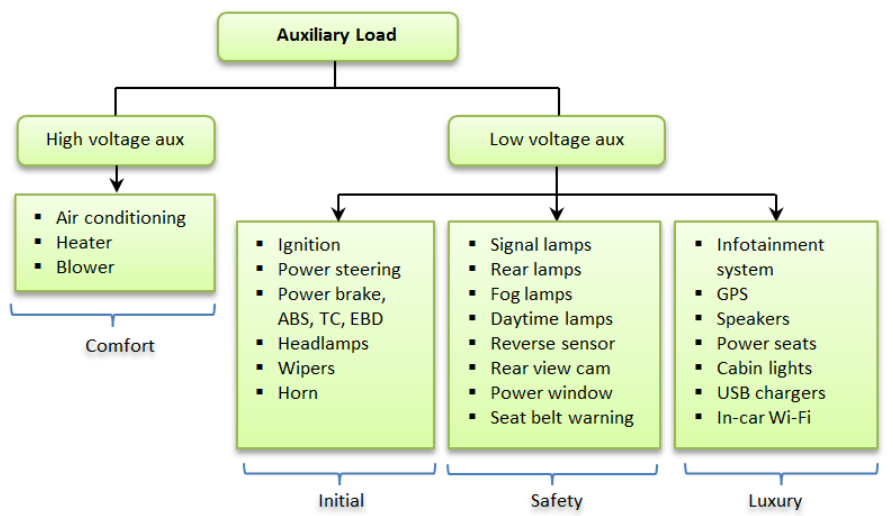

Fig. 5 Auxiliary loads categorization

\section{Design of EMS strategy}

An energy management strategy for BEV-001 is included in the model in three different driving modes; (1) sport mode, (2) comfort mode, and (3) eco mode. Mode is typically defined by three parameters; the speed or acceleration limit, the regenerative braking (beta) limit, and the comfort power limit. Globally, in European driving cycle, urban limit is at $50 \mathrm{~km} / \mathrm{h}$ and highway limit is at $120 \mathrm{~km} / \mathrm{h}$, while in US driving cycle is $\sim 100 \mathrm{~km} / \mathrm{h}$ and $\sim 60 \mathrm{~km} / \mathrm{h}$ respectively [13]. Our BEV-001 speed limit is adapted based on Malaysia national speed limit from Ministry of Works [17], highway speed limit is at $110 \mathrm{~km} / \mathrm{h}$, federal and state road at $90 \mathrm{~km} / \mathrm{h}$ while 50 to $70 \mathrm{~km} / \mathrm{h}$ at urban areas.

Power regenerates as much as $50 \%$ from braking in eco mode; the maximum possible for $\mathrm{HEV}$ or BEV [18]. Aggressive driving in sport mode will contribute as much as $35 \%$ energy while the least is in comfort mode (20\%) to ensure smooth driving. Heating, ventilating and air conditioning (HVAC) or comfort load as the second largest power consuming load, is set to maximum in sport mode, is reduced to $60 \%$ in comfort mode, and is kept at minimum in eco mode $(30 \%)$. However, active circulation during comfort and eco mode will assist to preserve the comfort level in comfort mode and minimally in eco mode. The summary of driving modes for BEV-001 is recaps in Table IV below. 
TABLE IV

BEV-001 DRIVING MODES

\begin{tabular}{|llll|}
\hline Parameter / Mode & Sport & Comfort & Eco \\
\hline Speed limit & $150 \mathrm{~km} / \mathrm{h}$ & $90 \mathrm{~km} / \mathrm{h}$ & $60 \mathrm{~km} / \mathrm{h}$ \\
Beta limit & $35 \%$ & $20 \%$ & $50 \%$ \\
Comfort power limit & $100 \%$ & $60 \%$ & $30 \%$ \\
\hline
\end{tabular}

Integrated driving mode

Fuzzy logic as one of the artificial intelligence (AI) techniques is employed in AI-Fuzzy mode in order to allow BEV-001 operates in integrated multi-mode driving. Our fuzzy logic controller (FLC) consists of a single input (driving cycle) and three outputs; speed limit ( $\left.\mathrm{v}_{\text {limit }}\right)$, beta limit $\left(\beta_{\text {limit }}\right)$, and comfort level $\left(\mathrm{P}_{\text {comf_limit }}\right)$. The advantage of this mode is that, the vehicle can operates in all range of speeds, beta's, and comfort levels without been confined by certain limit. Since the problem to solve by FLC is a boundary or limit problem, a triangle membership function (MF) is selected for all outputs. The input is a trapezium MF. The design of FLC is as illustrated in Fig. 6 below. The simulation test using NEDC driving cycle as presented in Fig. 7 shows the ability of FLC to produce the required outputs as previously described in Table IV.

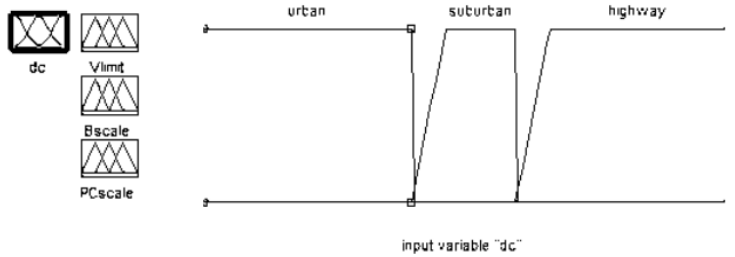

a)

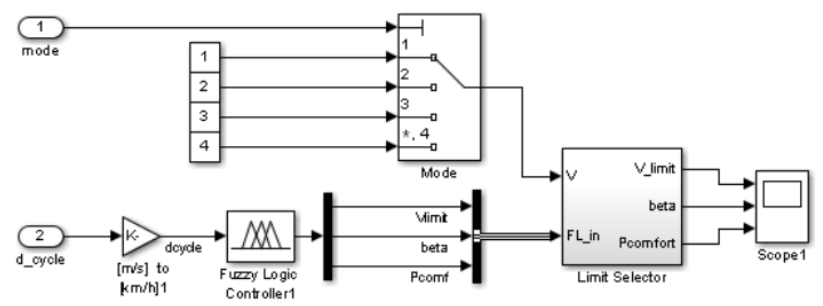

b)

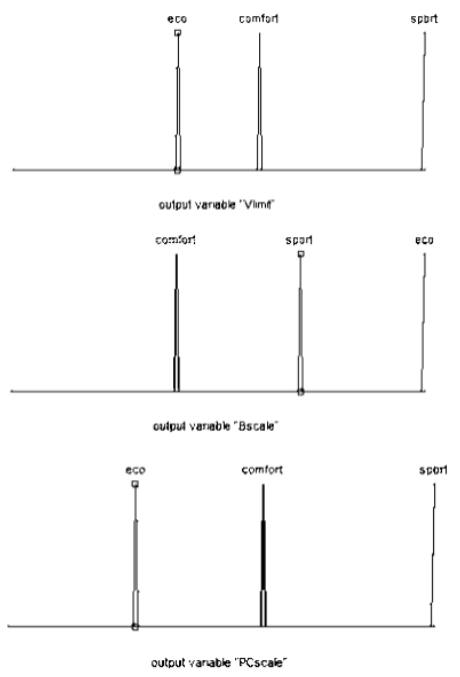

c)

Fig. 6 (a) Input MF, (b) FLC in driving mode, (c) output MFs.
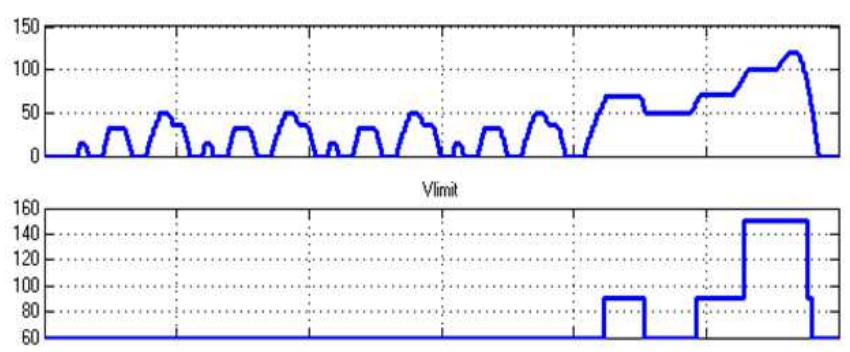

Blimit

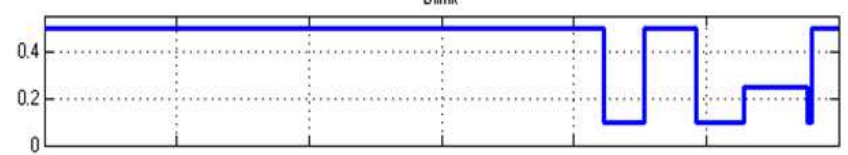

Pcomf_limit

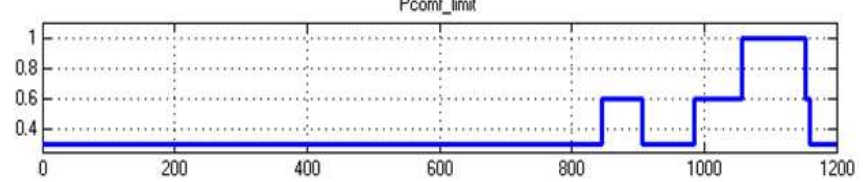

Fig. 7 FLC input (NEDC driving cycle) and outputs.

\section{RESULTS AND DISCUSSION}

The model is tested in NEDC under two weather conditions; (1) day, clear and hot temperature, and (2) night, rain and normal temperature. These two weathers are based on Malaysia average weather conditions throughout the year
[19]. The speed plots for BEV-001 in all four driving modes are as displayed in Fig. 8. The complete energy consumption in each load during every mode is compared and summarized in the following Table V (weather 1) and Table VI (weather 2).

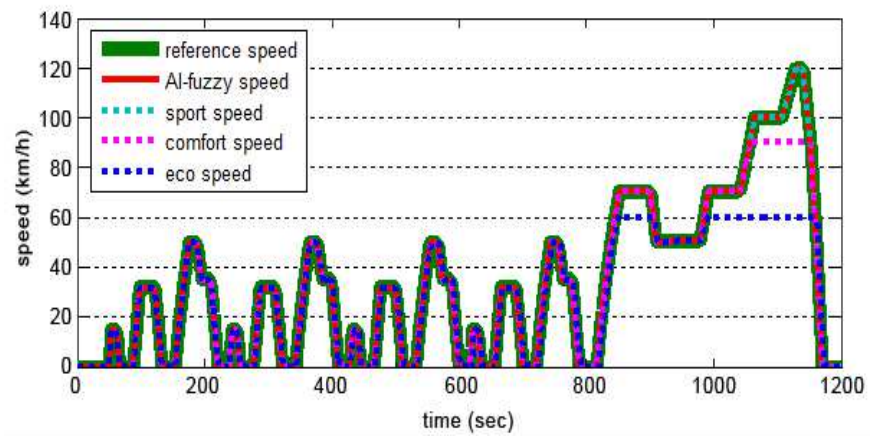

Fig. 8 Speed vs. time response for all modes in NEDC.

Fig. 8 demonstrates the speed-time response of BEV-001 in four driving modes against the reference speed of NEDC. All vehicle mode responses track the reference speed below their speed limits. However, in comfort and eco modes; once the speed limits have been reached, the responses are confined by the limits, and return back tracking after the reference speed is lower than the limits. The figure also 
verified that complete speed tracking only occurs during sport and AI-Fuzzy modes. It is mentioned in the EMS design that selection of speed limits is based on the driving environment. In eco and comfort modes, the user is confined by the speed limit of $60 \mathrm{~km} / \mathrm{h}$ and $90 \mathrm{~km} / \mathrm{h}$ which is respectively the urban and suburban speed limits. Eco mode is recommended for urban driving, comfort mode is for suburban driving and sport mode is for aggressive and highway driving.

Energy consumption in BEV-001 is calculated based on below equation;

$$
E_{\text {consumed }}=E_{\text {mot }}+\sum E_{\text {aux }}-E_{\text {regen }}
$$

where;

$E_{\text {mot }}$ propulsion load energy during motoring,

$E_{\text {regen }}=$ propulsion load energy during regenerating, and

$\Sigma E_{\text {aux }}=$ total auxiliary loads energy (consist of initial, safety, comfort and luxury auxiliaries).

TABLE V

COMPARISON OF ENERGY CONSUMPTION AND RANGE BETWEEN MODES IN WEATHER 1

\begin{tabular}{|l|rrrr|}
\hline \multirow{2}{*}{ Load } & \multicolumn{4}{|c|}{ Energy (Wh) } \\
& Sport & Comfort & Eco & AI- \\
& 1004.00 & 855.70 & 636.70 & 1004.00 \\
\hline Motoring & 64.20 & 21.82 & 79.87 & 96.61 \\
Regenerating & 5.44 & 5.05 & 4.85 & 5.44 \\
Initial aux & 25.78 & 25.61 & 25.46 & 25.78 \\
Safety aux & 1003.00 & 601.50 & 300.80 & 389.80 \\
Comfort aux & 51.87 & 51.87 & 51.87 & 51.87 \\
Luxury aux & $\mathbf{2 0 0 0 . 0 0}$ & $\mathbf{1 4 9 2 . 0 0}$ & $\mathbf{9 1 4 . 0 0}$ & $\mathbf{1 3 5 5 . 0 0}$ \\
\hline Energy Consumed & - & $\mathbf{5 0 8 . 0 0}$ & $\mathbf{1 0 8 6 . 0 0}$ & $\mathbf{6 4 5 . 0 0}$ \\
Energy Reduced & - & $\mathbf{2 5 . 4 0}$ & $\mathbf{5 4 . 3 0}$ & $\mathbf{3 2 . 2 5}$ \\
\% Reduced (relative to sport) & 10.91 & 10.51 & 9.29 & 10.91 \\
\hline Travelled range (km) & 72.70 & 75.17 & 78.97 & 76.22 \\
Residual range (km) & 83.61 & 85.68 & 88.26 & 87.13 \\
Total range (km) & - & $\mathbf{2 . 0 7}$ & $\mathbf{4 . 6 5}$ & $\mathbf{3 . 5 2}$ \\
\hline Additional range (km) & - & $\mathbf{2 . 4 8}$ & $\mathbf{5 . 5 7}$ & $\mathbf{4 . 2 1}$ \\
\% Increased (relative to sport) & & & &
\end{tabular}

TABLE VI

COMPARISON OF ENERGY CONSUMPTION AND RANGE BETWEEN MODES IN WEATHER 2

\begin{tabular}{|l|rrrr|}
\hline \multirow{2}{*}{ Load } & \multicolumn{4}{|c|}{ Energy (Wh) } \\
& Sport & Comfort & Eco & AI- \\
Fuzzy \\
\hline Motoring & 1004.00 & 855.70 & 636.70 & 1004.00 \\
Regenerating & 64.20 & 21.82 & 79.87 & 96.61 \\
Initial aux & 78.36 & 77.97 & 77.77 & 78.36 \\
Safety aux & 49.08 & 48.92 & 48.76 & 49.08 \\
Comfort aux & 192.70 & 115.60 & 57.82 & 73.92 \\
Luxury aux & 65.20 & 65.20 & 65.20 & 65.20 \\
\hline Energy Consumed & $\mathbf{1 2 7 6 . 0 0}$ & $\mathbf{1 0 9 3 . 0 0}$ & $\mathbf{7 5 8 . 0 0}$ & $\mathbf{1 1 2 5 . 0 0}$ \\
Energy Reduced & - & $\mathbf{1 8 3 . 0 0}$ & $\mathbf{5 1 8 . 0 0}$ & $\mathbf{1 5 1 . 0 0}$ \\
\% Reduced (relative to sport) & - & $\mathbf{1 4 . 3 4}$ & $\mathbf{4 0 . 5 9}$ & $\mathbf{1 1 . 8 3}$ \\
\hline Travelled range (km) & 10.91 & 10.51 & 9.29 & 10.91 \\
Residual range (km) & 115.90 & 125.60 & 142.50 & 117.19 \\
Total range (km) & 126.81 & 136.11 & 151.79 & 128.10 \\
\hline Additional range (km) & - & $\mathbf{9 . 3 0}$ & $\mathbf{2 4 . 9 8}$ & $\mathbf{1 . 2 9}$ \\
\% Increased (relative to sport) & - & $\mathbf{7 . 3 3}$ & $\mathbf{1 9 . 7 0}$ & $\mathbf{1 . 0 2}$ \\
\hline
\end{tabular}

The above strategies have decreased the energy consumption of the vehicle as presented in Table 5 and Table 6. Among the three individual modes (eco, comfort and sport), eco mode is the lowest in energy consumption, followed by comfort mode and finally sport mode, in both weather conditions. In relative to sport mode, $54.30 \%$ and $40.49 \%$ energy reductions in eco mode have produced $5.57 \%$ and $19.70 \%$ extra ranges during weather 1 and weather 2 respectively. Whilst, in comfort mode; $25.40 \%$ and $14.34 \%$ energy reduction contributes to $2.48 \%$ and $7.33 \%$ extra ranges during weather 1 and weather 2 . The results uncover that weather conditions is the energy saving influencing factor in BEV; our BEV-001 can run better mileage in weather 2 than weather 1 with about $30-40 \%$ increases in driving range. Though there are some increases in luxury, safety and initial loads in weather 2, however the decreases in comfort load (HVAC) energy consumption has significantly increased the driving range. Also, inevitable energy losses in BEV-001 model at DC-DC converter and inverter due to switching and PMAC operation based on its power efficiency map have resulted inefficiency in driving operation. This requires optimization strategy in order to have a better range which will be proposed in further research.

The proposed multi-mode driving (AI-Fuzzy mode) is apparently to improve the range in sport mode without being confined by any speed limit as in comfort and eco mode. The speed response in Fig. 5 demonstrates that this mode not only can perform at par with sport mode, but also produces large energy reduction $(32.25 \%)$ and $4.21 \%$ increases in driving range during weather 1 (Table V). These results prove the significant of multi-mode driving for a BEV in reducing the energy consumption and extending the driving range without downgrading its speed performance. Furthermore, this mode is an adaptive mode that will automatically select the driving parameters according to the vehicle speed. Therefore, this mode is suitable to all driving conditions.

\section{CONCLUSION}

This research has proven the significance of employing driving modes in extending the battery range of BEV. Driving mode represents the energy management strategy at supervisory level to increase the energy efficiency and reduce the energy consumption. The three driving modes; sport, comfort and eco employed in the BEV-001 model have their own advantages and suitable for different driving conditions; urban, suburban, and highway. The proposed integrated multi-mode driving based on fuzzy logic is an adaptive mode that suitable for all driving condition as it capable to automatically change the driving parameters based on the speed conditions. The results have proven its ability in reducing the energy consumption, and increasing the driving range without downgrading the speed performance.

\section{ACKNOWLEDGEMENTS}

The authors would like to thank the Faculty of Engineering, Universiti Putra Malaysia (UPM) for providing the facilities and conducive learning environment in 
conducting the research. The research is supported by the GP-IPS/2015/9462200-Universiti Putra Malaysia and HLP2013 scholarship, Ministry of Higher Education.

\section{REFERENCES}

[1] Larminie, J. and J. Lowry, Electric Vehicle Technology Explained. 2003, Chichester, UK: John Wiley \& Sons, Ltd.

[2] Mohd, T.A.T., M.K. Hassan, and W.M.K.A. Aziz, Mathematical Modeling and Simulation of an Electric Vehicle. Journal of Mechanical Engineering and Sciences (JMES), 2015. 8: p. 10 (13121321).

[3] Mohd, T.A.T., et al., Simulation based Study of Electric Vehicle Parameters. ARPN Journal of Engineering and Applied Sciences, 2015. 10(19): p. 6 (8541-8546).

[4] Khajepour, A., S. Fallah, and A. Goodarzi, Electric and Hybrid Vehicles Technologies, Modeling and Control: A Mechatronic Approach. 2014, Chichester, UK: John Wiley \& Sons Ltd.

[5] BMW. A Sporty Live Wire. The drive of the BMW i8. 2014 [cited $2016 \quad 17$ April 2016]; Available from: http://www.bmw.com/com/en/newvehicles/i/i8/2014/showroom/driv e.html.

[6] Jayk. 2016 Toyota Prius - Driving Impression And Review. 2016 [cited $2016 \quad 17$ April 2016]; Available from: http://www.topspeed.com/cars/toyota/2016-toyota-prius-drivingimpression-and-review-ar171880.html.

[7] Mitsubishi_Motors, i-MiEV, in Mitubishi i Sales Certification and Training. 2011: North America. p. 75.

[8] Florea, C. 2016 Nissan Leaf 2016 [cited 201617 April 2016]; Available from: http://www.topspeed.com/cars/nissan/2016-nissanleaf-ar171170.html.
[9] Frank, R., et al. A novel eco-driving application to reduce energy consumption of electric vehicles. in 2013 International Conference on Connected Vehicles and Expo (ICCVE). 2013.

[10] Kim, Y., I. Lee, and S. Kang, Eco Assist Techniques through Realtime Monitoring of BEV Energy Usage Efficiency. Sensors (Basel, Switzerland), 2015. 15(7): p. 14946-14959.

[11] Vatanparvar, K. and M.A.A. Faruque. Eco-Friendly Automotive Climate Control and Navigation System for Electric Vehicles. in 2016 ACM/IEEE 7th International Conference on Cyber-Physical Systems (ICCPS). 2016.

[12] Panday, A. and H.O. Bansal, A Review of Optimal Energy Management Strategies for Hybrid Electric Vehicle. International Journal of Vehicular Technology, 2014. 2014: p. 19.

[13] Barlow, T.J., et al., A Reference Book of Driving Cycles for used in the Measurement of Road Vehicle Emissions. Vol. 3. 2009, UK: TRL Limited. 284.

[14] Ehsani, M., Y. Gao, and A. Emadi, Modern Electric, Hybrid Electric, and Fuel Cell Vehicles Fundamentals, Theory and Design. Second Edition ed. 2010, New York, USA: CRC Press.

[15] Battery, W., Specification of Winston Rare Earth Lithium Yttrium Power Battery, in Winston Battery, W. Battery, Editor. 2011, Winston-Battery: Guangdong, China.

[16] Motors, Y., YASA 400, in YASA Motors, Y.M. Limited, Editor. 2014, YASA Motors Limited: England \& Wales, UK.

[17] KKRM, Motor Vehicles (Speed Limit) Rules 1989, in Speed Legislation. 2010, Kementerian Kerja Raya Malaysia: Malaysia. p. 4.

[18] Tie, S.F. and C.W. Tan, A review of energy sources and energy management system in electric vehicles. Renewable and Sustainable Energy Reviews, 2013. 20: p. 82-102.

[19] MOSTI. Malaysian Meteorological Department. 2016 [cited 201617 April 2016]; Available from: http://www.met.gov.my/. 